\section{Acridid (Orthoptera) fauna of agricultural ecosystem in some southern districts of Tamil Nadu, India}

\section{R. Ananthaselvi ${ }^{1}$, P. Suresh ${ }^{2}$, S. Janarthanan ${ }^{1}$, K.A.M. Karthikeyan ${ }^{1}$ \& I. Vijayakumar ${ }^{1}$}

1,2 Thiagarajar Centre for Entomological Science, Department of Zoology, Thiagarajar College (Autonomous), Madurai, Tamil Nadu 625009, India

Email: ${ }^{2}$ suresh_63@yahoo.com (corresponding author)

The richness of tropical insect fauna is beyond all earlier expectations (Stork 1988). Insects are the major components of animal diversity in terms of number of species in most of the habitats and ecosystems. With the growing awareness the world over for the need to understand and conserve biological diversity, there has been interest in evaluating the insect richness and diversity of the Indian fauna (Gadagkar et al. 1990; Muralirangan et al. 1993; Sanjayan 1993). Acridids cause extensive damage to both agroecosystem (COPR 1982) and rangeland ecosystem (Hewitt \& Onsanger 1983). The presence and dominance of grasshoppers appear to be influenced not only by the environmental gradients, but also by the species composition of plants as well (Kemp et al. 1990).

Among grasshoppers the acridids are the most important group thus their diversity and distribution in agricultural ecosystem was studied and reported here.

Acridids were collected by sweep-net technique from the agricultural ecosystem (crop fields and grasslands) of Madurai, Dindigul, Sivaganga, Virudhunagar, and Theni of the Southern districts in Tamil Nadu, India during the years 2004 and 2005. The collected species were identified adopting the conventional taxonomic procedures following the keys prescribed by Dirsh (1961) and Kirby (1914). Acridids were categorized based on their feeding guilds namely grass feeder (GF), dicot feeder (DF) and mixed feeder (MF) those feed on both the groups of plants. They were further designated as

Date of publication (online): 26 September 2009

Date of publication (print): 26 September 2009

ISSN $0974-7907$ (online) | 0974-7893 (print)

Editor: R.M. Sharma

Manuscript details:

Ms \# 01621

Received 17 August 2006

Final received 21 January 2008

Finally accepted 10 September 2009

Citation: Ananthaselvi, R., P. Suresh, S. Janarthanan, K.A.M. Karthikeyan \& I. Vijayakumar (2009). Acridid (Orthoptera) fauna of agricultural ecosystem in some southern districts of Tamil Nadu, India. Journal of Threatened Taxa 1(9): 491-492.

Copyright: () R. Ananthaselvi, P. Suresh, S. Janarthanan, K.A.M. Karthikeyan \& I. Vijayakumar 2009. Creative Commons Attribution 3.0 Unported License. JoTT allows unrestricted use of this article in any medium for non-profit purposes, reproduction and distribution by providing adequate credit to the authors and the source of publication.

Acknowledgement: The authors are grateful to the Management, Thiagarajar College for their support and encouragement.

OPEN ACGESS | FREE DOWNLOAD

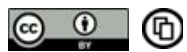

core and satellite species based on their abundance (Muralirangan et al. 1993).

Thirty-one species of acridids were identified belonging to the families Acrididae and Pyrgomorphidae (Table 1). The family Acrididae represented by 25 species (10 subfamilies and 22 genera) and the family Pyrgomorphidae comprised of six species (five genera). The highest number of species (six) recorded belong to subfamily Locustinae of family Acrididae. The feeding guild of recorded acridids revealed that nine species are grass feeders, one species is a dicot feeder and 21 species are mixed feeders. Among the Acridids collected, 18 species were recorded as core species and the other 13 species were designated as satellite species based on their moderate or sporadic distribution.

The species of the subfamily Acridinae, Oxyinae and Truxalinae were restricted to feed on grasses. All the species of the family Pyrgomorphidae were able to feed on dicot plants except Poekilocerus pictus which had a very strict feeding pattern. Though, recorded as a monophagous species, it feeds on some other plants too. All the grasshopper species were recorded throughout the study period including their temporal variation in abundance. The acridid P. pictus was recorded only during the months of September to December. Seasonal variation in grasshopper abundance is in relation to host plant availability. And this study indicates that variation in distribution of acridids as core and satellite to the availability of host plants, subject to prevailing ecological conditions.

\section{References}

Andersen, A.N., J.A. Ludwig, L.M. Lowe \& C.F. Rentz (2001). Grasshopper biodiversity and bioindicators in Australian tropical savannas: Responses to disturbance in Kakadu National Park. Australian Ecology 26: 213-222.

COPR (Centre for Overseas Pest Research) (1982). The Locust and Grasshopper Agricultural Manual. London: Centre for Overseas Pest Research, London, 690pp.

Dirsh, V.M. (1961). A preliminary revision of the families and subfamilies of Acridoidea (Orthoptera: Insecta). Bulletin of British Museum Natural Historty (Ent) 10(9): 351-419.

Gadagkar, R., K. Chandrasekara \& P. Nair (1990). Insect species diversity in tropics: Sampling methods and a case study. Journal of Bombay Natural History Society 87: 337-353.

Gandar, M.V. (1982). The dynamics and trophic ecology of grasshoppers (Acridoidea) in a South African savanna. Oecologia 54: 370-378.

Gangwere, S.K., M.C. Muralirangan \& M. Muralirangan (1997). The Bionomics of Grasshoppers, Katydids and Their Kin. CAB International, Wallingford, 1-3pp.

Gillon, Y. (1983). The invertebrates of the grass layer. In: Bouliere, F. (ed.). Ecosystems of the World 13: Tropical Savannas, Elsevier, Amsterdam, $311 \mathrm{pp}$.

Guo, Z., H. Li \& Y. Gan (2006). Grasshopper (Orthoptera: Acrididae) biodiversity and grassland ecosystems. Insect Science 13: 221-227.

Hewitt, G.B. \& J.A. Onsager (1983). Control of grasshoppers on rangeland in the United States - a perspective. J. Range. Manage 36: 202-207.

Janzen, D.H. (1981). Patterns of herbivory in a tropical deciducous forest. Biotropica 13(4): 271-282

Kemp, W.P., S.J. Harvey \& K.M. O'Neill (1990). Patterns of vegetation and grasshopper community composition. Oecologia 83: 299-308.

Kirby, W.F. (1914). The Fauna of British India including Ceylon and Burma. Orthoptera (Acrididae). Vol. 1: 276pp.

Muralirangan, M.C., P. Suresh \& P.D. Partho (1993). Observation on the grasshopper species diversity, density and distributional pattern in peninsular India. The Entomologist 112(3\&4): 201-210.

Sanjayan, K.P. (1993). An overview of heterogeneity in grasshopper assemblages. Hexapoda 5: 133-144. 
Table 1. Distribution, feeding guild and abundance of acridid species

\begin{tabular}{|c|c|c|c|}
\hline & Species & Feeding Guild & Abundance \\
\hline & Family: Pyrgomorphidae & & \\
\hline 1. & Atractomorpha crenulata (Fabricius) & MF & Core \\
\hline 2. & Chrotogonus oxypterus (Blanchard) & MF & Core \\
\hline 3. & Orthacris robusta Kevan & MF & Satellite \\
\hline 4. & Orthacris maindroni Bolivar & MF & Core \\
\hline 5. & Pyrgomorpha bispinosa Walker & MF & Core \\
\hline \multirow[t]{2}{*}{6.} & Poekilocerus pictus (Fabricius) & DF & Core \\
\hline & $\begin{array}{l}\text { Family: Acrididae } \\
\text { Subfamily: Acridinae }\end{array}$ & & \\
\hline 7. & Acrida exaltata (Walker) & GF & Core \\
\hline 8. & Phlaeoba infumata Burnner & GF & Satellite \\
\hline & Subfamily: Catantopinae & & \\
\hline 9. & Diabolocatantops pinguis (Walker) & MF & Core \\
\hline 10. & Xenocatantops humilis humilis (Serville) & MF & Satellite \\
\hline 11. & Stenocatantops splendens (Thunberg) & MF & Satellite \\
\hline \multirow[t]{2}{*}{12.} & Catantops furrugineus (Walker) & MF & Satellite \\
\hline & Subfamily: Cyrtacanthacridinae & & \\
\hline 13. & Cyrtacanthacris tatarica tatarica (Linnaeus) & MF & Core \\
\hline 14. & Anacridium flavescens (Fabricius) & MF & Core \\
\hline 15. & Pachyacris violascens (Walker) & MF & Satellite \\
\hline & Subfamily: Eyprepocnemidinae & & \\
\hline 16. & Eyprepocnemis alacris alacris (Serville) & MF & Core \\
\hline 17. & Heteracris pulcher (Bolivar) & MF & Satellite \\
\hline & Subfamily: Gomphocerinae & & \\
\hline 18. & Leva cruciata Bolivar & MF & Core \\
\hline 19. & Leva indica (Bolivar) & MF & Satellite \\
\hline & Subfamily: Hemiacridinae & & \\
\hline 20. & Spathosternum prasiniferum prasiniferum (Walker) & GF & Core \\
\hline & Subfamily: Locustinae & & \\
\hline 21. & Aiolopus thalassinus thalassinus (Fabricius) & GF & Core \\
\hline 22. & Aiolopus thalassinus tamulus (Fabricius) & GF & Core \\
\hline 23. & Gastrimargus africanus africanus (Saussure) & MF & Satellite \\
\hline 24. & Morphacris fasciata sulcata (Thunberg) & MF & Satellite \\
\hline 25. & Oedaleus senegalensis (Krauss) & MF & Satellite \\
\hline 26. & Trilophidia annulata (Thunberg) & MF & Core \\
\hline & Subfamily: Oxyinae & & \\
\hline 27. & Gesonula punctiforns (Stal) & GF & Core \\
\hline 28. & Oxya fuscovittata (Marshal) & GF & Core \\
\hline 29. & Oxya nitidula (Walker) & GF & Core \\
\hline 30 & Subfamily: Tropidopolinae & MF & Satellite \\
\hline & Subfamily: Truxalinae & & \\
\hline 31. & Truxalis indica (Bolivar) & GF & Satellite \\
\hline
\end{tabular}

GF - Grass Feeder; DF - Dicot Feeder; MF - Mixed Feeder

Stork, N.E. (1988). Insect diversity: facts, fiction and speculation. Biological Journal of the Linnean Society 35: 321-337.

Wolda, H. (1983). Diversity, diversity indices and tropical cockroaches. Oecologia 58: 290-298.

Yin, X. (1984). Grasshoppers and Locusts from Qinghai-Tibet Plateau of China. Science Press, Beijing, 287pp. 